\title{
Characterization of Fuji Apples from Different Harvest Dates and Storage Conditions from Measurements of Volatiles by Gas Chromatography and Electronic Nose
}

\author{
Gemma Echeverría, ${ }^{\dagger}$ Eva Correa,,${ }^{\ddagger}$ Margarita Ruiz-Altisent, $₫$ \\ JORDI GRAELL, ${ }^{\dagger}$ JAUME PUY ${ }^{\S}$ AND LUISA LÓPEZ ${ }^{*}, \dagger$ \\ Área Postcosecha, CeRTA, UdL-IRTA, and Departamento de Química, UdL, \\ Avda. Rovira Roure 191, 25198 Lleida, Spain, and Lab. Propiedades Físicas, ETSIA, \\ Universidad Politécnica de Madrid, 28040 Madrid, Spain
}

\begin{abstract}
Volatile compounds in Fuji apples harvested at two different maturities were measured at harvest and after 5 and 7 months of cold storage $\left(1^{\circ} \mathrm{C}\right)$ in four different atmospheres. When the samples were characterized by both chromatographic measurements of volatiles and responses of an electronic nose, the analyses showed a clear separation between fruits from different storage conditions (a normal cold atmosphere and three controlled atmospheres). During poststorage, the apples were left to ripen for 1,5 , and 10 days at $20^{\circ} \mathrm{C}$ before analytical measurements were done involving headspace-gas chromatography methods and electronic nose type quartz crystal microbalances. Electronic nose responses registered by seven different sensors were used to classify the apples using principal component analysis. It was possible to identify the samples from different storage periods, days of shelf life, and harvest dates, but it was not possible to differentiate the fruits corresponding to different cold storage atmospheres.
\end{abstract}

KEYWORDS: Fuji apples; volatile compounds; cold storage; gas chromatography; electronic nose

\section{INTRODUCTION}

Maturity at harvest and cold storage conditions can have a very important effect on the sensory acceptation of apples (1). Background color, starch index, soluble solid content, and flesh firmness are currently used in the apple industry to determine maturity at harvest. The starch index and $a^{*}+b^{*}$ parameter were therefore regarded as good indicators of fruit maturity for Fuji apples $(2,3)$. Controlled atmosphere storage is a wellestablished technique for extending the postharvest life of apples. Meheriuk (4) reported that the best conditions for Fuji storage in a controlled atmosphere are $1.0-2.5 \% \mathrm{O}_{2}$ and $0.7-2.0 \% \mathrm{CO}_{2}$. However, controlled atmosphere storage may also reduce volatile aroma production in this cultivar (5). This effect of controlled atmosphere storage tends to increase with low $\mathrm{O}_{2}$ and high $\mathrm{CO}_{2}$ concentrations (6).

Despite the changes in their volatile profile as apples progress through maturation, at harvest and during subsequent storage (7), these changes are not normally used by the apple industry as indicators of maturity because traditional methods for analyzing volatile compounds (HS-GS-MS) require expensive instrumentation and are difficult to undertake $(8)$.

* To whom correspondence should be addressed. Tel: +34 737026 51. Fax: +34 732383 01. E-mail: mluisa@tecal.udl.es.

$\dagger$ Area Postcosecha, CeRTA, UdL-IRTA.

Lab. Propiedades Físicas, ETSIA, Universidad Politécnica de Madrid. $\S$ Departamento de Química, UdL.
Over 200 volatile compounds have been identified in apples (9). In Fuji apples, Kakiuchi et al. (10) identified 37 volatile aroma compounds. Fellman et al. (11) reported that 2-methylbutyl acetate was the predominant compound involved in the ripening of this cultivar. The high number of volatile compounds prevents a simple interpretation of volatile measurements, although only a few of the compounds involved have possible causal effects with respect to flavor. Even considering only the major contributors to sensory attributes, such as 2-methylbutyl acetate, ethyl 2-methylbutanoate, hexyl acetate, and ethanol, in the case of Fuji apple (12), a skilled analyst is still required to measure these components by headspace-GC methodology.

Electronic nose technology could overcome some of the difficulties associated with traditional methods of measuring volatile compounds. Furthermore, this type of analysis would be rapid, nondestructive, and continuous. Few studies have related volatile compound analysis and electronic nose measurements in apple. Smith et al. (13) used a prototype electronic sensor array to discriminate between five apple varieties. Ripeness in Royal Gala apples has been related to classical volatile measurements using data derived from electronic volatile sensing (8).

Electronic nose type QCMs are piezoelectric quartz crystal oscillators coated with a sensing cover. Adsorption of odor molecules by these covers leads to changes in the resonant frequencies of these devices due to changes in mass. Different covers can be used, and changes in resonant frequencies in the 
Table 1. Codes for Samples Corresponding to Different Treatments

\begin{tabular}{cllc}
\hline harvest & cold storage atmospheres & storage period & shelf life period \\
\hline $\mathrm{H} 1(185 \mathrm{DAFB})$ & $\mathrm{AIR}\left(21 \% \mathrm{O}_{2} / 0.03 \% \mathrm{CO} \mathrm{CO}_{2}\right)$ & HARV (both harvests) & $\mathrm{SL} 1\left(1\right.$ day at $\left.20^{\circ} \mathrm{C}\right)$ \\
$\mathrm{H} 2(195 \mathrm{DAFB})$ & $\mathrm{SCA}\left(3 \% \mathrm{O}_{2} / 3 \% \mathrm{CO}_{2}\right)$ & $\mathrm{S} 5(5$ storage months) & $\mathrm{SL2}\left(5\right.$ days at $\left.20^{\circ} \mathrm{C}\right)$ \\
& $\mathrm{ULO} 1\left(1 \% \mathrm{O}_{2} / 1 \% \mathrm{CO}_{2}\right)$ & $\mathrm{S} 7(5$ storage months $)$ & $\mathrm{SL3}\left(10\right.$ days at $\left.20^{\circ} \mathrm{C}\right)$ \\
& $\mathrm{ULO} 2\left(1 \% \mathrm{O}_{2} / 2 \% \mathrm{CO}_{2}\right)$ & &
\end{tabular}

presence of different odors can be analyzed (14). However, there is currently little published research on the application of QCM sensors to measure apple volatiles. Herrmann et al. (15) used this electronic nose type to detect and discriminate between the different volatile organic compounds formed during the postharvest ripening of apples.

The aim of this study was to determine the applicability of electronic nose type QCM for the measurement of volatile compounds in Fuji apples, both at harvest and after cold storage in different atmospheres.

\section{MATERIALS AND METHODS}

Samples. Apples, from 5 year old Fuji Nagafu 6 (Malus domestica Borkh.) trees grown in Lleida (NE Spain) on M-9 EMLA rootstock, were harvested on two commercial dates: 185 (H1) and 195 (H2) DAFB. Fruit maturity was determined by measuring the background color $\left(\mathrm{a}^{*}+\mathrm{b}^{*}\right)$ and starch index (1-5 scale) according to the methods described by Echeverría et al. (3).

At each harvest date, one lot of 68 apples was selected and later analyzed after 1 (SL1), 5 (SL2), and 10 (SL3) days of shelf life at 20 ${ }^{\circ} \mathrm{C}$. At each harvest date, 20 apples were transported overnight to the Universidad Politécnica de Madrid for sampling by electronic nose, and another 48 apples were subjected to volatile compounds analysis (40 fruits) and ethylene and $\mathrm{CO}_{2}$ analysis (eight fruits) in the Centre UdL-IRTA in Lleida. These 68 fruits were the same throughout the shelf life period, because these analyses are nondestructive.

Immediately after harvest, four lots of approximately 280 apples per harvest date were stored at $1{ }^{\circ} \mathrm{C}$ and $92 \% \mathrm{RH}$ in cold storage chambers. Four cold storage conditions were used as follows: one SCA, $3 \% \mathrm{O}_{2}+2 \% \mathrm{CO}_{2}$; two ULO1, $1 \% \mathrm{O}_{2}+1 \% \mathrm{CO}_{2}$, and ULO2, $1 \% \mathrm{O}_{2}$ $+2 \% \mathrm{CO}_{2}$; and one normal atmosphere (AIR), $21 \% \mathrm{O}_{2}+0.03 \% \mathrm{CO}_{2}$.

Fruit samples were removed from each storage atmosphere after 5 (S5) and 7 (S7) months and analyzed after 1 (SL1), 5 (SL2), and 10 (SL3) days of shelf life at $20{ }^{\circ} \mathrm{C}$. Table 1 presents all of the sample codes.

Reagents and Chemicals. The standards of the different volatile compounds studied were supplied by Sigma-Aldrich (Steinheim, Germany), Fluka (Chemie, Switzerland), Merck (Darmstadt, Germany), Avocado Research Chemicals Ltd. (Madrid, Spain), and Extrasynthese (Genay, France). The CAS number, source, and purity of each compound are specified in Table 2 . The 2-methylbutyl propanoate and hexyl butanoate were synthesized by estherification of propionic acid and butyric acid with 2-methy-1-butanol and 1-hexanol, respectively. All of the other chemicals and reagents used were of analytical grade.

Analysis of Volatile Compounds. The dynamic headspace method was used to extract of volatile compounds from intact apples (four replicates, $2 \mathrm{~kg}$ each one) according to the method described by López et al. (16), although with a shorter $(8 \mathrm{~h})$ extraction time. The identification and quantification of volatile compounds were performed on a GC H-P 5890 series II (Hewlet-Packard Co., Barcelona, Spain) using a cross-linked FFAP capillary column $(50 \mathrm{~m} \times 0.2 \mathrm{~mm} \times 0.33$ $\mu \mathrm{m})$. The oven program was set at $70{ }^{\circ} \mathrm{C}(1 \mathrm{~min})$, and the temperature was first raised by $3{ }^{\circ} \mathrm{C} \mathrm{min}-1$ to $142{ }^{\circ} \mathrm{C}$ and later by $5{ }^{\circ} \mathrm{C} \min ^{-1}$ to $225^{\circ} \mathrm{C}$. It was then kept constant for $10 \mathrm{~min}$ at this latter temperature. Helium was used as the carrier gas. Compounds were detected using a FID at $240{ }^{\circ} \mathrm{C}$. These compounds were identified by comparing their respective retention indices with those of standards and by enriching apple extract with authentic samples. The quantification was made using butylbenzene (assay $>99.5 \%$, Fluka) as internal standard. Spectra were recorded with a Hewlett-Packard 3398GC Chemstation. The identity
Table 2. Chemical Standards Used in the Study

\begin{tabular}{lll}
\hline \multicolumn{1}{c}{ compounds } & CAS no. & \multicolumn{1}{c}{ source } \\
\hline methyl acetate & $79-20-9$ & $99 \%$ Fluka \\
ethyl acetate & $141-79-6$ & $99.5 \%$ Fluka \\
ethanol & $200-578-6$ & Merck \\
tert-butyl propanoate & $20487-40-5$ & $99 \%$ Fluka \\
propyl acetate & $109-60-4$ & $98 \%$ Fluka \\
2-methylpropyl acetate & $110-19-0$ & $99 \%$ Avocado \\
1-propanol & $71-23-8$ & $99 \%$ Fluka \\
ethyl butanoate & $105-54-4$ & $98 \%$ Fluka \\
ethyl 2-methylbutanoate & $7452-79-1$ & $95 \%$ Fluka \\
butyl acetate & $000123-86-4$ & $98.5 \%$ Fluka \\
2-methylpropyl propionate & $540-42-1$ & $98 \%$ Aldrich \\
+ 2-methyl-1-propanol & $78-83-1$ & $99.5 \%$ Fluka \\
hexanal & $66-25-1$ & $98 \%$ Avocado \\
2-methylbutyl acetate & $123-92-2$ & $98 \%$ Aldrich \\
1-butanol & $71-36-3$ & $99.5 \%$ Fluka \\
butyl propanoate & $590-01-2$ & $99 \%$ Aldrich \\
4-methyl-2-pentanol & $108-11-2$ & $99 \%$ Fluka \\
amyl acetate & $628-68-7$ & $99 \%$ Fluka \\
2-methyl-1-butanol & $13-94-5$ & $98 \%$ Fluka \\
D-limonene & $5989-27-5$ & $98 \%$ Aldrich \\
butyl butanoate & $109-21-7$ & $99 \%$ Fluka \\
butyl 2-methylbutanoate & $15706-73-7$ & $97 \%$ Aldrich \\
ethyl hexanoate & $123-66-0$ & $99 \%$ Aldrich \\
amyl alcohol & $71-41-0$ & $99 \%$ Aldrich \\
hexyl acetate & $142-92-7$ & $99 \%$ Fluka \\
hexyl propanoate & 1040036 & $99.64 \%$ Extrasynthese \\
1-hexanol & $000111-27-3$ & $99 \%$ Fluka \\
(E)-2-hexenol & $928-95-0$ & $95 \%$ Fluka \\
butyl hexanoate & $626-82-4$ & $98 \%$ Aldrich \\
hexyl 2-methylbutanoate & $49-7729-970$ & $95 \%$ Aldrich \\
propionic acid & $79-09-4$ & $99 \%$ Aldrich \\
butyric acid & $107-92-6$ & $99 \%$ Aldrich \\
& & \\
\hline
\end{tabular}

of the volatile compounds was confirmed by comparing their GC retention indices and their mass spectra with those of an external standard injected in a Hewlett-Packard 5890 gas chromatograph (GCMS) under the same conditions and by comparing spectra with those of a database (NIST HP59943C original mass spectral library). GCMS were equipped with the same capillary column as in the GC-FID analyses that were used. Mass spectra were obtained by electron impact ionization at $70 \mathrm{eV}$. Helium was used as the carrier gas. Results were expressed as $\mu \mathrm{g} \mathrm{kg}^{-1}$ (16).

To measure carbon dioxide $\left(\mathrm{CO}_{2}\right)$ and ethylene production $\left(\mathrm{C}_{2} \mathrm{H}_{4}\right)$, eight apples were divided into two replicates and weighed (about $1 \mathrm{~kg}$ per replication). They were then placed in $5 \mathrm{~L}$ jars and continuously aerated with humidified air at a rate of $\sim 2 \mathrm{~L} \mathrm{~h}^{-1}$ at $20^{\circ} \mathrm{C}$. Ethylene production was measured by taking gas samples from effluent air with a $1 \mathrm{~mL}$ syringe. Gas samples were injected into a Hewlett-Packard 5890 GC-FID equipped with an alumina column 80/100 $(2 \mathrm{~m} \times 3 \mathrm{~mm})$ (Teknokroma, Barcelona, Spain). Gas analyses were conducted isothermally at $100{ }^{\circ} \mathrm{C}$. Nitrogen was used as the carrier gas. Compounds were detected with a flame ionization detector at $180^{\circ} \mathrm{C}$. Carbon dioxide production was directly measured by connecting effluent tubes to an infrared analyzer unit (Beckman Industrial, model 868, Tea, SD).

Electronic Nose. The "LibraNose" electronic nose (Technobiochip, Italy) has seven (s1, s3, s4, s5, s6, s7, and s8) QCM sensors coated with different pyrrolic macrocycle solid state films, combined to each sensor with different metals (Mn, Cop- $\mathrm{NO}_{2}, \mathrm{Ru}, \mathrm{Sn}, \mathrm{Rh}, \mathrm{Cr}$, and $\mathrm{Co}$ ), respectively. The sensors were located inside a $20 \mathrm{~mL}$ measuring chamber.

The headspace for the experiments carried out with fruit was generated by placing a whole fruit inside a tightly closed $0.75 \mathrm{~L}$ box. 
Table 3. Effect of Shelf Life Period (1, 5, and 10 Days at $20^{\circ} \mathrm{C}$ ) on Emission of Volatile Compounds in Fuji Apples for Two Harvest Dates (H1 and $\mathrm{H} 2)^{a}$

\begin{tabular}{|c|c|c|c|c|c|c|c|c|}
\hline \multirow[b]{2}{*}{ compounds $(\mu \mathrm{g} / \mathrm{kg})$} & \multirow[b]{2}{*}{ codes } & \multirow[b]{2}{*}{$\mathrm{RI}^{b}$} & \multicolumn{3}{|c|}{185 DAFB (H1) } & \multicolumn{3}{|c|}{195 DAFB $(\mathrm{H} 2)$} \\
\hline & & & 1 day & 5 days & 10 days & 1 day & 5 days & 10 days \\
\hline methyl acetate & $\mathrm{ma}$ & 834 & $4.4 a$ & $2.0 \mathrm{~b}$ & $1.2 \mathrm{c}$ & $1.4 \mathrm{c}$ & $2.9 a$ & $2.1 \mathrm{~b}$ \\
\hline ethyl acetate & ea & 898 & $4.8 \mathrm{~b}$ & $8.0 \mathrm{a}$ & $4.4 \mathrm{~b}$ & $4.8 b$ & $12.2 \mathrm{a}$ & $5.9 b$ \\
\hline ethanol & etOH & 932 & $12.2 \mathrm{a}$ & $7.9 b$ & $9.0 \mathrm{~b}$ & $4.2 \mathrm{C}$ & $15.0 \mathrm{a}$ & $8.1 b$ \\
\hline tert-butyl propanoate & tbp & 964 & $2.4 a$ & $1.2 \mathrm{~b}$ & $0.8 \mathrm{~b}$ & $0.7 \mathrm{~b}$ & $1.2 a$ & $0.9 b$ \\
\hline propyl acetate & $\mathrm{pa}$ & 984 & $1.4 \mathrm{c}$ & $2.6 \mathrm{~b}$ & $7.2 \mathrm{a}$ & $2.2 b$ & $2.5 \mathrm{a}$ & $1.7 \mathrm{c}$ \\
\hline 2-methylpropyl acetate & $2 \mathrm{mpa}$ & 1020 & $2.4 \mathrm{~b}$ & $2.6 \mathrm{~b}$ & $5.7 a$ & $2.9 a$ & $2.6 a$ & $1.5 \mathrm{~b}$ \\
\hline 1-propanol & $\mathrm{pOH}$ & 1036 & $0.9 \mathrm{c}$ & $1.1 \mathrm{~b}$ & $2.1 \mathrm{a}$ & $1.2 \mathrm{~b}$ & $1.9 a$ & $0.9 \mathrm{c}$ \\
\hline ethyl butanoate & $\mathrm{eb}$ & 1043 & trace & $0.6 a b$ & $0.9 a$ & $0.5 a$ & trace & $0.6 \mathrm{a}$ \\
\hline ethyl 2-methylbutanoate & e2mb & 1059 & $67.1 \mathrm{c}$ & $193.7 a$ & $136.5 \mathrm{~b}$ & $121.2 \mathrm{~b}$ & $229.4 a$ & $113.1 b$ \\
\hline butyl acetate & $\mathrm{ba}$ & 1082 & $9.0 \mathrm{a}$ & $7.0 \mathrm{ab}$ & $3.7 \mathrm{~b}$ & $9.0 \mathrm{a}$ & $3.7 \mathrm{~b}$ & $4.4 b$ \\
\hline $\begin{array}{l}\text { 2-methylpropyl propionate + } \\
\text { 2-methyl-1-propanol }\end{array}$ & $\begin{array}{l}2 \mathrm{mpp}+ \\
2 \mathrm{mpOH}\end{array}$ & 1091 & $1.1 \mathrm{~b}$ & $1.0 \mathrm{~b}$ & $2.0 \mathrm{a}$ & $1.0 \mathrm{a}$ & $0.6 \mathrm{c}$ & $0.8 b$ \\
\hline hexanal & hexal & 1101 & $2.2 \mathrm{a}$ & $0.6 \mathrm{~b}$ & $0.7 \mathrm{~b}$ & trace & $0.6 a$ & trace \\
\hline 2-methylbutyl acetate & $2 m b a$ & 1131 & $200.4 a$ & $157.4 b$ & $207.5 a$ & $197.1 \mathrm{a}$ & $84.2 \mathrm{~b}$ & $61.3 \mathrm{c}$ \\
\hline 1-butanol & buOH & 1144 & $1.3 a$ & $1.6 \mathrm{a}$ & $2.3 a$ & $2.4 a$ & $2.5 a$ & $0.8 \mathrm{~b}$ \\
\hline butyl propanoate & bp & 1148 & $7.9 a$ & $7.0 \mathrm{a}$ & $4.2 \mathrm{~b}$ & $11.7 a$ & $2.4 \mathrm{~b}$ & $2.1 \mathrm{~b}$ \\
\hline 4-methyl-2-pentanol & $4 m 2 p$ & 1163 & $3.0 \mathrm{a}$ & $0.6 \mathrm{c}$ & $0.8 \mathrm{~b}$ & $0.6 \mathrm{~b}$ & $0.9 a$ & $0.6 \mathrm{~b}$ \\
\hline amyl acetate & aa & 1183 & $1.5 b$ & $1.4 \mathrm{~b}$ & $2.5 \mathrm{a}$ & $2.4 a$ & $2.3 a$ & $0.7 \mathrm{~b}$ \\
\hline 2-methylbutyl propanoate & $2 m b p$ & 1199 & $2.5 \mathrm{~b}$ & $2.7 \mathrm{~b}$ & $3.8 \mathrm{a}$ & $2.8 \mathrm{a}$ & $1.1 \mathrm{c}$ & $1.4 \mathrm{~b}$ \\
\hline 2-methyl-1-butanol & $2 \mathrm{mbOH}$ & 1210 & $22.5 b$ & $20.8 b$ & $33.5 a$ & $29.0 \mathrm{a}$ & $15.1 \mathrm{~b}$ & $11.0 \mathrm{c}$ \\
\hline D-limonene & limon & 1219 & $1.3 a$ & $1.1 \mathrm{~b}$ & $1.0 \mathrm{~b}$ & $0.8 \mathrm{c}$ & $1.7 \mathrm{a}$ & $1.3 \mathrm{~b}$ \\
\hline butyl butanoate & $\mathrm{bb}$ & 1228 & $1.5 b$ & $1.2 \mathrm{~b}$ & $3.3 a$ & $2.9 a$ & $1.6 \mathrm{~b}$ & $1.0 \mathrm{~b}$ \\
\hline butyl 2-methylbutanoate & b2mb & 1240 & $3.3 \mathrm{~b}$ & $3.1 \mathrm{~b}$ & $6.1 \mathrm{a}$ & $4.9 a$ & $1.5 b$ & $2.3 \mathrm{~b}$ \\
\hline ethyl hexanoate & eh & 1243 & ND & ND & $1.5 a$ & $1.2 \mathrm{a}$ & $2.2 \mathrm{a}$ & ND \\
\hline amyl alcohol & $\mathrm{aOH}$ & 1253 & trace & trace & trace & trace & ND & ND \\
\hline hexyl acetate & ha & 1283 & $9.9 a$ & $6.7 a$ & $6.6 \mathrm{a}$ & $12.9 \mathrm{a}$ & $4.7 \mathrm{~b}$ & $3.3 b$ \\
\hline hexyl propanoate & $\mathrm{hp}$ & 1349 & $0.7 \mathrm{c}$ & $1.4 \mathrm{~b}$ & $5.0 \mathrm{a}$ & $4.5 \mathrm{a}$ & $0.5 \mathrm{~b}$ & trace \\
\hline 1-hexanol & $\mathrm{hOH}$ & 1358 & $0.9 \mathrm{~b}$ & $0.5 b$ & $3.4 a$ & 3.9 & 4.1 & trace \\
\hline (E)-2-hexenol & EheOH & 1415 & ND & ND & ND & ND & ND & ND \\
\hline butyl hexanoate & bh & 1423 & trace & $0.5 \mathrm{~b}$ & $1.0 \mathrm{a}$ & $4.6 \mathrm{a}$ & trace & trace \\
\hline hexyl butanoate & $\mathrm{hb}$ & 1426 & $0.8 \mathrm{a}$ & $0.6 a$ & $1.0 \mathrm{a}$ & $3.4 a$ & trace & trace \\
\hline hexyl 2-methylbutanoate & $\mathrm{hmb}$ & 1436 & $0.8 \mathrm{~b}$ & $1.4 \mathrm{~b}$ & $4.1 \mathrm{a}$ & $7.6 \mathrm{a}$ & $0.7 \mathrm{~b}$ & $0.8 \mathrm{~b}$ \\
\hline total volatile compounds & & & $366.2 b$ & $436.3 a$ & $461.8 \mathrm{a}$ & $441.8 \mathrm{a}$ & $398.1 b$ & $226.6 c$ \\
\hline
\end{tabular}

${ }^{a}$ Letters $(a-c)$ indicate which values in each row differed significantly $(p \leq 0.05)$ for the same harvest date. Volatile compounds not detected are indicated as ND, and amounts of $<0.5 \mu \mathrm{g} / \mathrm{kg}$ are indicated as trace. ${ }^{b} \mathrm{RI}$ : retention index for volatile compounds.

Two keys on the lids facilitated transfers from the headspace to the electronic nose. Generation of the headspace took $1 \mathrm{~h}$; a flow of $0.2 \mathrm{~L}$ $\min ^{-1}$ was generated by suction using the micropump inside the electronic nose; generating responses from the QCM sensor took 7-8 min. This took the effluent through one of the valves and to the sensors. At the same time, the second valve opened allowing the carrier gas to enter and thereby preventing the creation of depressions inside the recipient. When the sample reached the sensors, its oscillation frequency was modified. The micropump then generated another flow of $0.2 \mathrm{~L}$ $\mathrm{min}^{-1}$ in order to eliminate traces of the sample from the sensor chamber. The carrier gas used to transfer the headspace and clean the sensor chamber was dry synthetic air (assay > 99.999\%).

Statistical Analysis. A factorial design considering shelf life period, storage period, atmosphere condition, harvest date, and replication was used to statistically analyze volatile compounds and electronic nose responses. All results were tested by variance analysis (GLM-analysis of variance procedure) using the SAS program package (17). Means were separated by the LSD test at $p \leq 0.05$. PCA was developed to provide an overview of samples using Unscrambler vers. 6.11. (18). Samples were characterized according to their volatile emissions and their response to electronic nose sensors. Volatile compound codes are indicated in Table 3. PLS was used to correlate volatile compounds and sensor measurements. Volatile compounds were used as $\mathrm{X}$ variables and correlated with measurements from each sensor ( $\mathrm{Y}$ variables) by PLS1 regression. Volatile compounds used as $\mathrm{X}$ variables were also correlated with the sensors that were most closely related to the volatile measurements (s4, s5, and s7) by PLS2 regression, which provided a compact overview of the correlation results. As a pretreatment, data were centered and weighed by the inverse of the standard deviation of each variable in order to avoid dependence on measured units (19). Full cross-validation was run as a validation procedure.

\section{RESULTS AND DISCUSSION}

Use of Electronic Nose Sensor Measurements to Characterize Samples. Figure 1 shows the PCA results from a model containing the harvest fruits characterized by the sensor responses (six samples $\times$ seven variables). PC1 and PC2 accounted for 59 and $28 \%$ of the total variance, respectively. Late-harvested fruits (H2) appear in the upper part of the graph, and early-harvested fruits (H1) appear in the lower part of the graph. Fruit samples from the two harvest dates were therefore distinguished by PC2, mainly dependent on s4 and s3 sensor responses. This result suggests that electronic nose responses for the s4 and s3 sensors vary according to harvest date. When comparing Figure 1A,B, late-harvested fruits tend to exhibit high values in the responses of the s3, s4, and s5 sensors (both fruits and sensors appear at the top of the respective graphs), while early-harvested fruits exhibit low values for the same sensors but a high value for the 57 sensor.

Fruits from 185 DAFB (H1) also showed a sequential distribution over PC1 from day 1 (SL1) to day 10 (SL3) of ripening at $20^{\circ} \mathrm{C}$ (Figure 1A). Thus, the electronic nose seems to be able to sense the ripening of early-harvested fruits at 20 ${ }^{\circ} \mathrm{C}$. The postharvest shelf life period had an effect on both total volatile emission and the individual volatile compounds in Fuji apples. In fact, these early-harvested fruits evidenced increasing volatile emission throughout postharvest ripening at $20{ }^{\circ} \mathrm{C}$ (Table 3). After 1,5 , and 10 days at $20^{\circ} \mathrm{C}$, apples had a total volatile emission of $366.2,436.3$, and $461.8 \mu \mathrm{g} \mathrm{kg}^{-1}$, respectively. The increment in total volatile emission between 1 and 

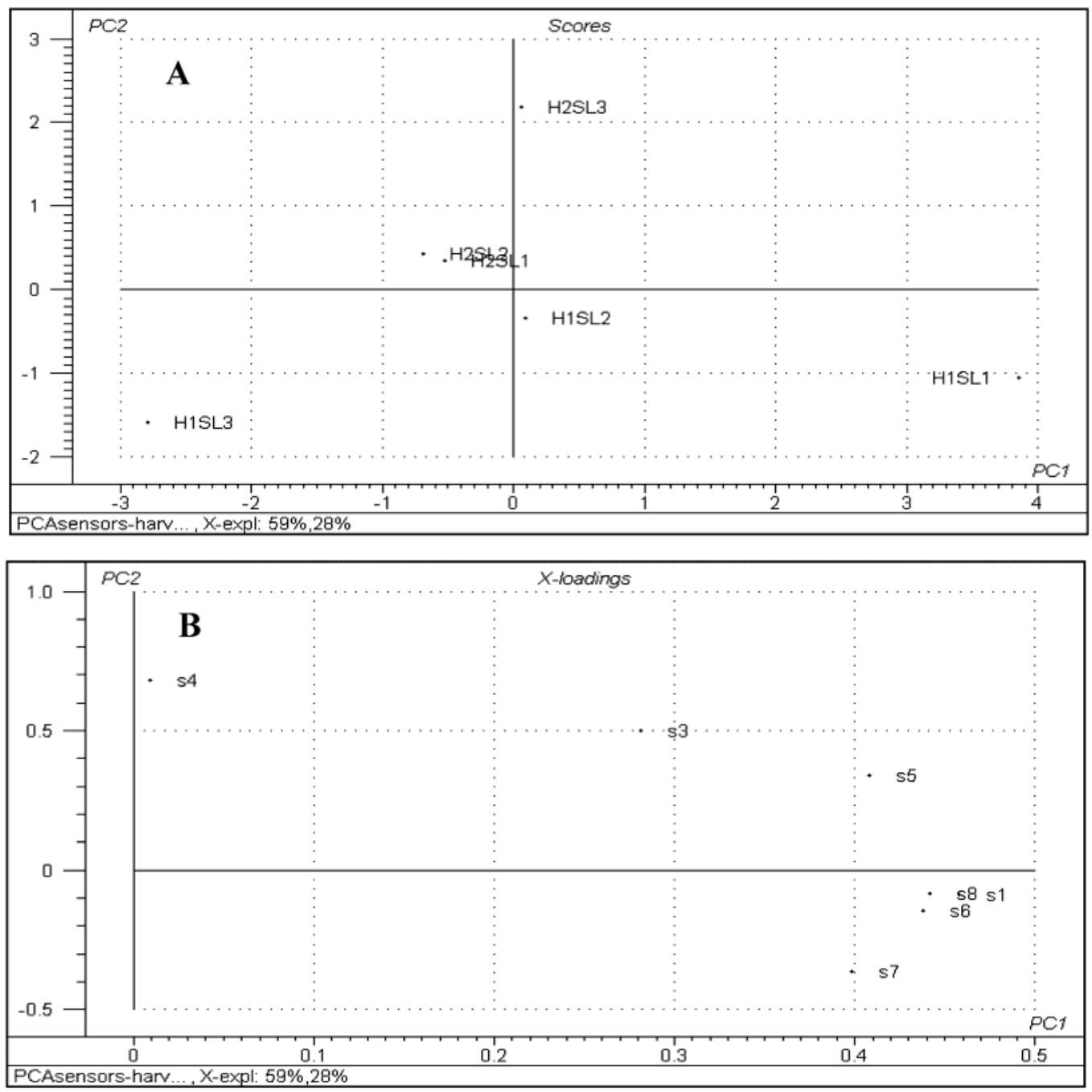

Figure 1. Scores and loadings plot of PC1 vs PC2 from a PCA model of electronic nose data at harvest. Sample codes are labeled in Table 1. Electronic sensor codes are defined in the Material and Methods section.

5 days at $20{ }^{\circ} \mathrm{C}$ was mainly due to an increase in the concentration of five volatile compounds: ethyl acetate, 1-propanol, ethyl 2-methylbutanoate, hexyl propanoate, and butyl hexanoate. However, the volatile compounds increment between 5 and 10 days at $20^{\circ} \mathrm{C}$ was due to a higher concentration of 15 volatile compounds: propyl acetate, 2-methylpropyl acetate, 1-propanol, ethyl butanoate, 2-methylpropyl propionate + 2-methyl-1-propanol, 2-methylbutyl acetate, amyl acetate, 2-methylbutyl propanoate, 2-methyl-1-butanol, butyl butanoate, butyl 2-methylbutanoate, ethyl hexanoate, hexyl propanoate, 1-hexanol, butyl hexanoate, and hexyl 2-methylbutanoate (Table 3). This greater ester emission throughout postharvest ripening was also reported by Fellman et al. (11) in Fuji apples after 1 and 7 days at $25^{\circ} \mathrm{C}$.

In the case of late-harvested apples, the total volatile emission was $441.8,398.1$, and $226.6 \mu \mathrm{g} \mathrm{kg}^{-1}$, after 1,5 , and 10 days at $20{ }^{\circ} \mathrm{C}$, respectively (Table 3). The concentration of 13 volatile compounds was highest after 1 day at $20^{\circ} \mathrm{C}$; after 5 days, 10 volatile compounds presented their highest concentrations; none of the volatile compounds exhibited their maximum concentration after 10 days at $20^{\circ} \mathrm{C}$. This decrease in the concentration of volatile compounds could indicate that these late-harvested apples, which had reached a more advanced stage of maturity (starch index $=4.7 ; \mathrm{a}^{*}+\mathrm{b}^{*}=34.9$ ) as opposed to earlyharvested apples ( starch index $=4.1 ; \mathrm{a}^{*}+\mathrm{b}^{*}=28.5$ ), showed a reduced ability to produce volatile compounds during ripening.
The proportion of linolenic acid in lipids from postclimacteric apples is lower than from preclimacteric apples (20). This could explain the decrease in straight chain esters in the postclimacteric apples, because one of the main biosynthetic pathways in straight chain esters is $\beta$-oxidation of fatty acids such as linoleic acid (21). This result also confirms previous findings by Echeverría et al. (22), which suggest that substrate availability could play an important role in volatile compounds development during the ripening of Fuji apples.

Figure 1 does not reflect the variation in the total volatile emission of $\mathrm{H} 2$ samples during ripening since the $\mathrm{PC} 1$ scores of the different $\mathrm{H} 2$ shelf life samples are not well-spread. This suggests that either the lower volatile emission by $\mathrm{H} 2$ samples was not well-detected by the sensors or that the sensor responses were not directly related to the total volatile concentrations of the volatiles detected in the chromatographic analysis. Obviously, the ability of different volatiles to influence the sensor responses varies and this does not exclude the possibility of other factors also influencing sensor responses. Thus, Herrmann et al. (15) indicated that QCM electronic noses produce different responses for determined volatile compounds according to the films used to coat their sensors, but they also reported similar responses from four pure apple flavor components (ethyl 2-methylbutanoate, 2-hexenal, hexanol, and S-limonene).

PCA results from a model containing all of the samples (from harvest and after cold storage) characterized by the sensor 


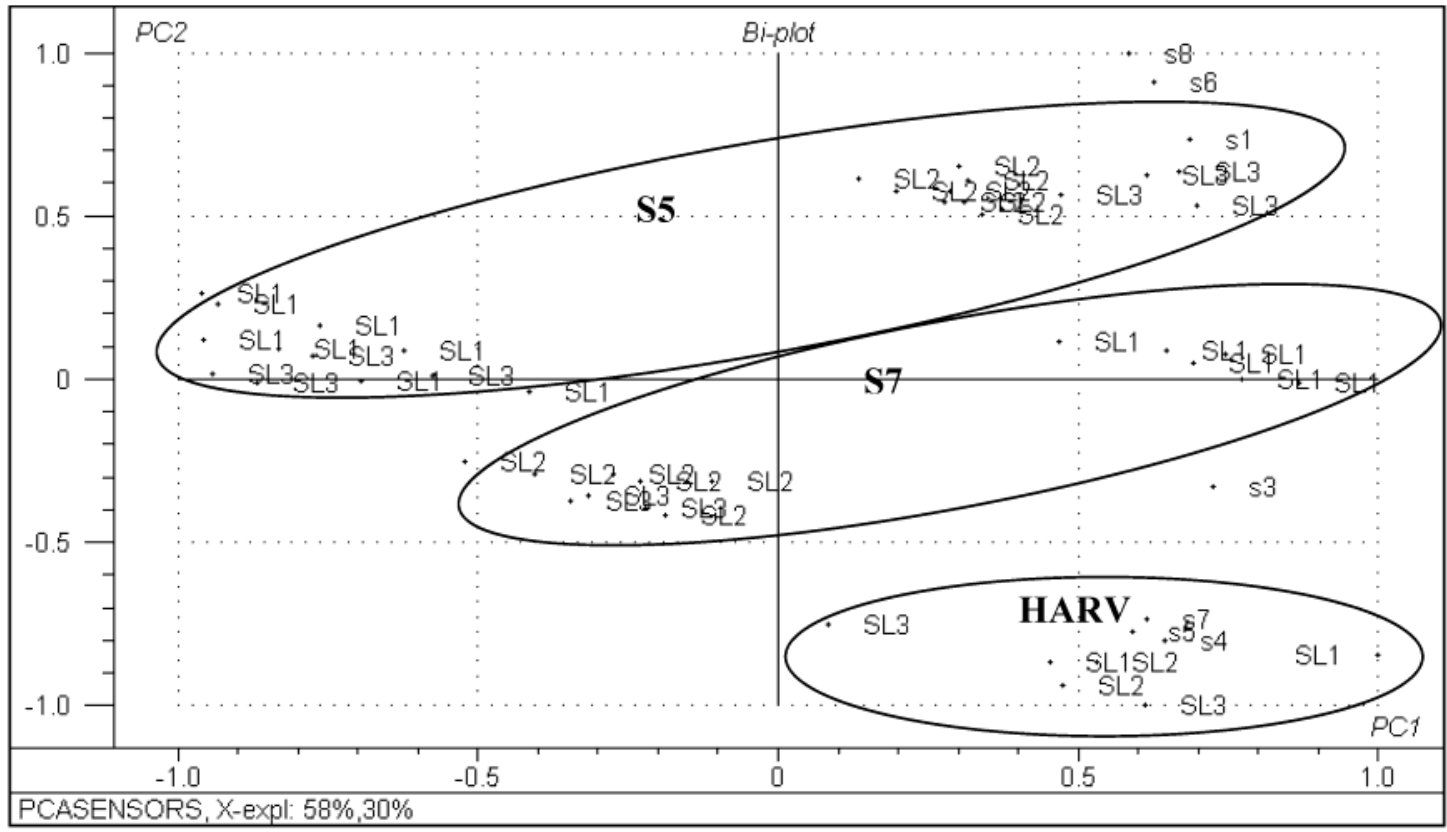

Figure 2. Biplot (scores and loadings) of PC1 vs PC2 from a PCA model of electronic nose data at harvest and after cold storage. Sample codes are labeled in Table 1.

responses are shown in Figure 2. PC1 and PC2 accounted for 58 and $30 \%$ of the total variance, respectively, with a total of five interpretable principal components from the cross-validation procedure. Only the first two PCs are visualized in Figure 2. The scores plot of PC1 vs PC2 shows a clear distinction between samples pertaining to harvest (HARV) and to the different cold storage periods ( 5 months, S5, and 7 months, S7), although there was no discrimination with respect to specific cold storage conditions. In fact, S7 samples lie between HARV and S5, suggesting that the sensor measurements reach their highest values at S5, decrease at S7, and are lowest at HARV. This sensor behavior is similar to that for volatile emission reported in our previous work on Fuji apples (12): extending storage from 5 to 7 months reduces both the total volatile fraction and the concentrations of the main volatile compounds.

Figure 2 also shows the ability of the electronic nose to differentiate the ripening process. As previously commented, the ripening of harvest samples is least well-differentiated due to the effect of the late-harvested samples (Figure 1). For the cold storage samples, differences during shelf life are clearly reflected in Figure 2. Samples at day 1 of shelf life (SL1) appear on the left of the PC space after 5 months of cold storage (S5), while they appear on the right after 7 months (S7). Thus, PC1 exhibits maximum sensibility with respect to ripening. Notice that after 5 months of storage, SL2 and SL3 samples tend to be close to samples corresponding to S7SL1, while after 7 months of storage, SL2 and SL3 samples are close to samples corresponding to S5SL1.

The loadings plot of PC1 vs PC2 (also included in Figure 2) shows that all of the sensors correlated positively with PC1, which is mainly helpful for sensing the shelf life period. With respect to PC2, the sensors could be split into two groups: s1, s8, and s6 (which positively correlated with PC2) and the rest of the sensors (which negatively correlated with PC2). The differences in the measurements between these groups were related to storage periods.

Finally, the electronic nose was able to differentiate between harvest dates after cold storage of fruits although this is not seen in Figure 2 since the splitting with respect to $\mathrm{H} 1-\mathrm{H} 2$ appears in PC3.
Analysis of Samples Characterized by Combining both Electronic Nose and Gas Chromatographic Measurements. We also carried out a PCA combining the values of the volatile compounds and sensor responses (Figure 3). Full crossvalidation was used in the validation step of the model. PC1 and PC2 accounted for 24 and 14\% of the total variance, respectively. The scores plot for PC1 vs PC2 (Figure 3A) differentiated between harvest samples and samples stored in normal cold atmosphere (AIR) and in controlled atmosphere conditions (SCA, ULO1, and ULO2).

The loadings plot (Figure 3B) shows the majority of volatile compounds located in the upper part. Comparison between Figure $\mathbf{3 A}$ and Figure $\mathbf{3 B}$ shows that it was possible to distinguish between samples from harvest on the basis of the combined effect of higher concentrations of 2-methyl-1-butanol $(2 \mathrm{mbOH}), 2$-methyl-1-propanol $(2 \mathrm{mpOH}), 2$-methylbutyl acetate (2mba), 2-methylbutyl propanoate ( $2 \mathrm{mbp}$ ), hexanal (hexal), and 4-methyl-2-pentanol ( $4 \mathrm{~m} 2 \mathrm{p})$ and higher values registered by the s7, s4, and s3 sensors. The intermediate group, corresponding to samples from controlled atmospheres, was characterized by greater concentrations of (E)-2-hexenol (EheOH), ethanol $(\mathrm{etOH})$, methyl acetate (am), and propanol $(\mathrm{pOH})$ and higher values registered by the s1, s6, and s8 sensors. Samples from AIR treatments were mainly characterized by butyl butanoate (bb), amyl acetate (aa), hexyl butanoate (bh), butyl acetate (ba), ethylene $\left(\mathrm{C}_{2} \mathrm{H}_{4}\right)$, 1-butanol (buOH), butyl hexanoate (bh), 1-hexanol (hOH), amyl alcohol $(\mathrm{aOH})$, hexyl 2-methylbutanoate (hmb), tert-butyl propanoate (tbp), butyl 2-methylbutanoate (b2mb), hexyl propanoate (hp), and $\mathrm{CO}_{2}$ production $\left(\mathrm{CO}_{2}\right)$ and by the low values registered by all sensors. These results indicate that apples stored in the AIR atmosphere were characterized by greater concentrations of the majority of volatile compounds and confirmed results for the same variety previously obtained by Echeverría et al. (12).

Relationship between Sensor Response and Volatile Emissions. Separate PLS1 regression models were run in an attempt to correlate the sensor measurements with the chromatographically detected volatile emissions. The $\mathrm{X}$ matrix contained the volatile compounds, and the Y matrix contained each of the sensors. Table 4 gathers the main statistics of the resulting PLS1 

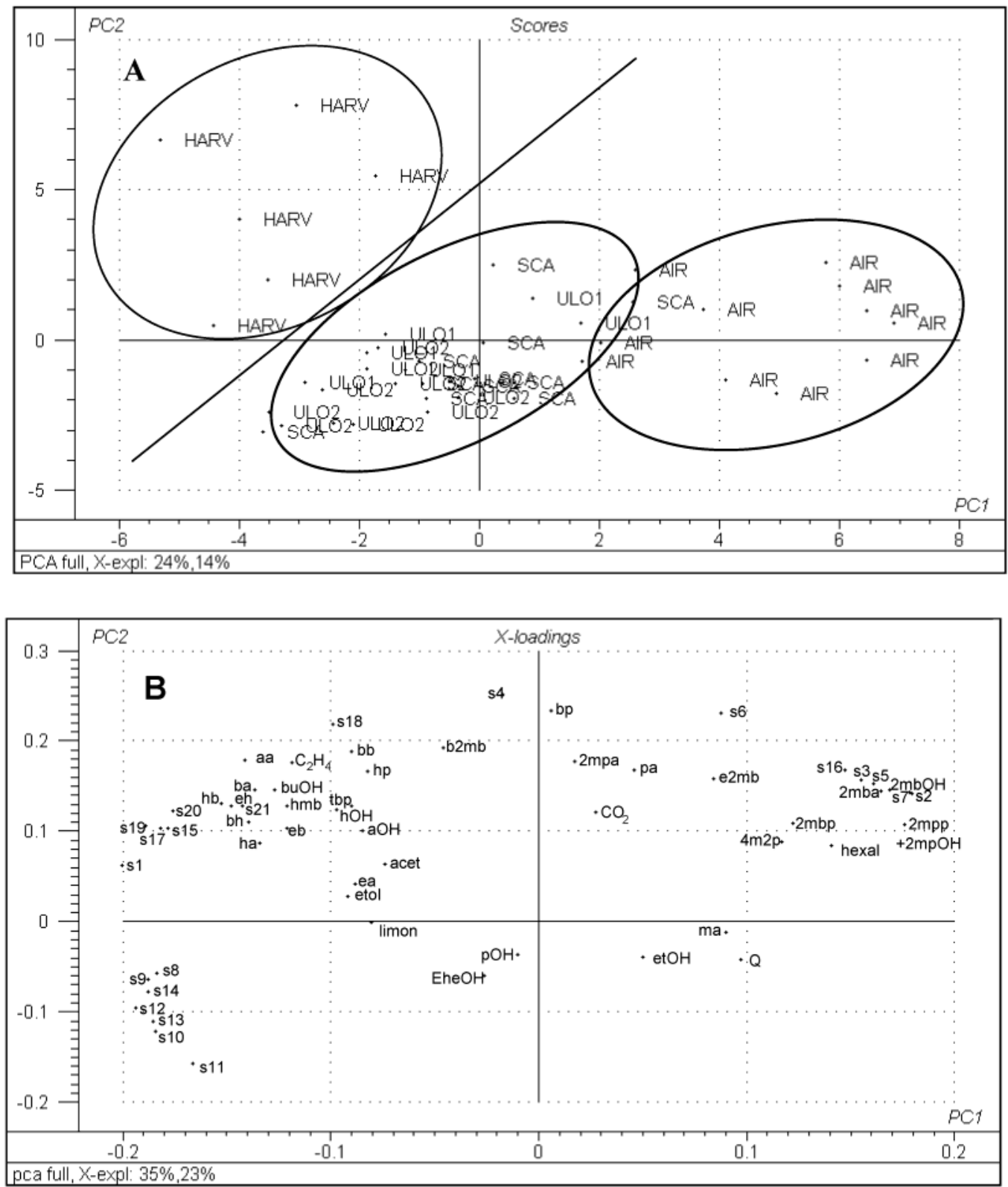

Figure 3. Scores and loadings plot of PC1 vs PC2 from a PCA model of volatile compounds and electronic nose data at harvest and after cold storage. Sample and volatile compounds codes are labeled in Tables 1 and 3, respectively. Electronic sensors and ethylene and carbon dioxide production codes are defined in the Material and Methods section.

Table 4. Statistics of the PLS1 Regression Models Made of Sensor Responses ( $Y$ Variables) in Terms of the Volatile Data ${ }^{a}$

\begin{tabular}{ccc}
\hline Y variable & $\begin{array}{c}\text { \% of } Y \text { variance } \\
\text { explained at } \\
\text { calibration }\end{array}$ & $\begin{array}{c}\text { \% of } Y \text { variance } \\
\text { explainedat } \\
\text { validation }\end{array}$ \\
\hline s1 & 27.8 & \\
s3 & 40.9 & \\
s4 & 60.2 & 26.9 \\
s5 & 58.5 & 14.6 \\
s6 & 23.5 & \\
s7 & 72.7 & 52.1 \\
s8 & 29.8 &
\end{tabular}

${ }^{a}$ In all of the models, two PLS factors have been considered. ${ }^{b}$ Sensor codes are explained in the Materials and Methods section.

models. The percentage of variance of the sensor measurements explained by the volatile emissions depended on the sensor considered. The values reported in the table were obtained using two PLS factors. Only the s4, s5, and s7 sensors correlated with the volatile measurements at validation. However, the crossvalidation results should be taken with caution since the low number of samples and the different conditions applied to each one, as was explained in the Materials and Methods section, decrease the confidence of cross-validation to estimate the ability of the model to predict the sensor measurements. The results reported for the calibration step can be considered as qualitative, which for the present discussion seems to be enough, but two PLS factors correspond in any case to the steepest decreasing part of the plot of the residual variance of the $\mathrm{Y}$ data vs the number of PLS factors, before a break in this decreasing tendency was observed.

The s4, s5, and s7 sensors seemed to be the ones that correlated best with certain volatile measurements, both at calibration and at validation steps. The loadings plot of PC1 vs PC2 for these models is very similar, which indicates that all of these sensors are closely related. To have an overview of these plots, Figure 4 shows the loadings plot of PC1 vs PC2 


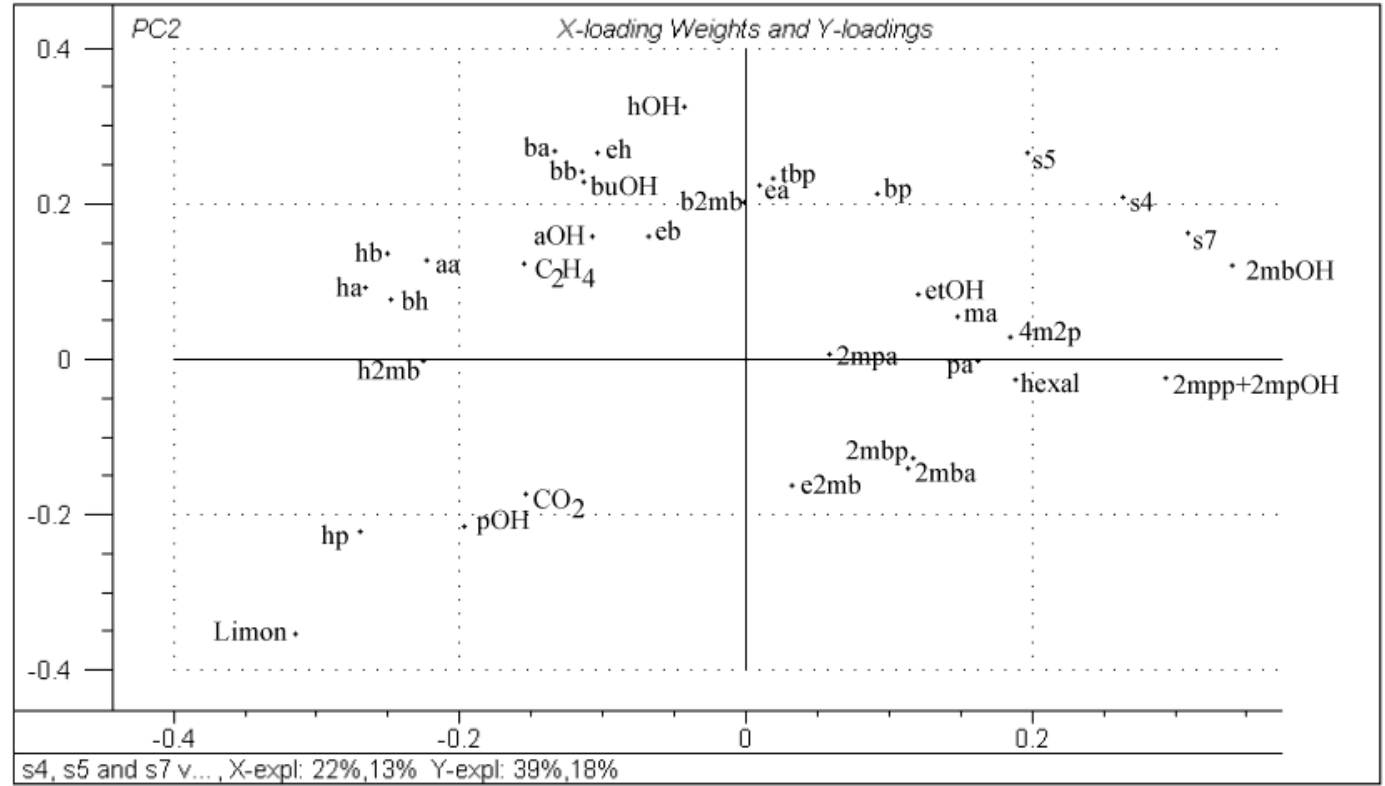

Figure 4. Loadings plot of PC1 vs PC2 from a PLS2 model of s4, s5, and s7 sensor responses (Y) vs volatile compounds (X) measured at harvest and after cold storage. Volatile compound codes are labeled in Table 3. Electronic sensor and ethylene and carbon dioxide production codes are defined in the Material and Methods section.

for a PLS2 model incorporating all of the sensors. In any case, the volatiles most closely related to the measurements of these sensors seemed to be 2-methyl-1-butanol, 2-methylpropyl propionate, and 2-methyl-1-propanol. It should be noted that 2-methyl-1-butanol is the most important alcohol in the volatiles of Fuji apples. The s4, s5, and s7 sensors also appeared close to each other in Figure 3, indicating high values for these sensors and also for the volatiles 2-methyl-1-butanol, 2-methylpropyl propionate, and 2-methyl-1-propanol in harvest samples. Results presented in Figure $\mathbf{4}$ also agree with those shown in Figure 3. This indicates that s7 is well-influenced by ethyl 2-methylbutanoate, 2-methyl-1-propanol, 2-methylpropyl propionate, 2-methylbutyl acetate, and 2-methylbutyl propanoate. With regard to this, it is important to emphasize that the contribution of any given compound to total aroma depends on its concentration and odor threshold (the level at which a compound can be detected by smell) in the fruit. Ethyl 2-methylbutanoate and 2-methylbutyl acetate must have a direct impact upon Fuji flavor, because these compounds constitute more than $50 \%$ of the total volatile fraction present in Fuji apples (12). Herrmann et al. (15) also obtained a good QCM sensor response with respect to ethyl 2-methylbutanoate in postharvest ripening apples.

The rest of the sensors (s1, s3, s6, and s8) showed a low explained variance with respect to volatile measurements during both the calibration and the validation steps. This result suggested the complementarity or independence of the sample information obtained from these sensors ( $1, \mathrm{~s} 3$, s6, and s8) or from chromatographically measured volatile emissions. The different behaviors of s4, s5, and s7 sensors from s1, s3, s6, and $\mathrm{s} 8$ sensors reflected the influence of the sensor coating upon the response of the sensor in question. Similar results were also obtained by Herrmann et al. (15); they used the same type of electronic nose but different sensor coatings and analyzed two apple flavors: ethyl 2-methylbutanoate and S-limonene.

\section{ABBREVIATIONS USED}

AIR, normal cold storage; DAFB, days after full bloom; FID, flame ionization detector; GC, gas chromatography; HS-GS-
MS, headspace gas chromatography-mass spectrometry; PCA, principal component analysis; PC1, first principal component; PC2, second principal component; PLS, partial least squares regression; QCM, quartz crystal microbalance; RH, relative humidity; SCA, standard controlled atmosphere; ULO1, ultralow oxygen controlled atmosphere with $1 \% \mathrm{CO}_{2}$; ULO2, ultralow oxygen controlled atmosphere with $2 \% \mathrm{CO}_{2}$.

\section{ACKNOWLEDGMENT}

We thank NUFRI, SAT, and CATAFRUIT, SA, for providing fruits and facilities. We thank Montse Lloveras Arcas, Departamento de Química, UdL, for mass spectrometry analysis.

\section{LITERATURE CITED}

(1) Jager, A.; Johnson, D.; Hohn, E. Determination and prediction of optimum harvest date of apples and pears. COST 94: Proceedings of a Meeting of the Working Group on Optimum Harvest Date, Lofthus, Norway, 1994; pp 7-8.

(2) Fan, X.; Mattheis, J. P.; Patterson, M. E.; Fellman, J. K. Evaluation of 'Fuji' apple ground color at harvest as a predictor of post-storage fruit quality. In Proceedings of 7th International CA Conference-I; Mitcham, E. J., Ed.; University of California: Davis, CA, 1997; pp 42-49.

(3) Echeverría, G.; Graell, J.; López, M. L. Effect of harvest date and storage conditions on quality and aroma production of 'Fuji' apples. Food Sci. Technol. Int. 2002, 8 (6), 351-360.

(4) Meheriuk, M. SCA storage conditions for apples, pears and nashi. In Proceedings of the 6th International CA Research Conference; Blanpied, G. D., Ed.; Cornell University: Ithaca, New York, 1993; Vol. 2, pp 819-858.

(5) Seong-Jin, Ch. M.; Jee Eun, K. The change in aroma production of 'Fuji' apple fruits as influenced by CA storage. J. Korean Soc. Hortic. Sci. 1999, 40 (1), 61-64.

(6) Yahia, E. M.; Liu, F. W.; Acree, T. E. Changes of some odoractive volatiles in controlled atmosphere-stored apples. J. Food Qual. 1990, 13, 185-202.

(7) Song, J.; Bangerth, B. Production and development of volatile aroma compounds of apple fruits at different times of maturity. Acta Hortic. 1994, 368, 150-157. 
(8) Young, H.; Rossier, K.; Wang, M.; Miller, M. Characterization of Royal Gala apple aroma using electronic nose technologypotential maturity indicator. J. Agric. Food Chem. 1999, 47, $5173-5177$.

(9) Dimick, P. S.; Hoskin, J. C. Review of apple flavor. State of the art. Crit. Rev. Food Sci. Nutr. 1983, 18, 387-409.

(10) Kakiuchi, M.; Moriguchi, S.; Fukuda, H.; Ichimura, N.; Kato, Y.; Banba, Y. Composition of volatile compounds of apple fruits in relation to cultivars. J. Jpn. Soc. Hortic. Sci. 1986, 55, 280289.

(11) Fellman, J. K.; Miller, T. W.; Mattinson, D. S.; Mattheis, J. P. Factors that influence biosynthesis of volatile flavor compounds in apple fruits. HortSci. 2000, 35 (6), 1026-1033.

(12) Echeverría, G.; Fuentes, M. T.; Graell, J.; López, M. L. Relationships between volatile production, fruit quality and sensory evaluation of 'Fuji' apples stored in different atmospheres by means of multivariate analysis. J. Sci. Food Agric. 2003, 84, 5-20.

(13) Smith, L.; Metcalfe, E.; Taylor, S. Olfactory analysis of posthavest apples by an electronic sensing device. Acta Hortic. 1999, 485, 341-349.

(14) Deshpande, S. S. Biosensors in food quality evaluation. In Nondestructive Food Evaluation. Techniques to Analyze Properties and Quality; Gunasekaran, S., Ed.; Marcel Dekker: New York, 2001; pp 335-417.

(15) Herrmann, U.; Jonischkeit, T.; Bargon, J.; Hahn, U.; Qian-Yi, L.; Schalley, C. A.; Vogel Vögtle, U. Monitoring apple flavor by use of quartz microbalances. Anal. Bioanal. Chem. 2002, 372, 611-614.

(16) López, M. L.; Lavilla, T.; Recasens, I.; Riba, M.; Vendrell, M. Influence of different oxygen and carbon dioxide concentrations during storage on production of volatile compounds by Starking
Delicious apples. J. Agric. Food Chem. 1973, 21, 1 (9), 155166.

(17) SAS. Statistical Analysis System. User's Guide: Statistics (PCDOS 6.04); SAS Institute Inc.: Cary, NC, 1988.

(18) CAMO ASA. Unscrambler Users Guide, ver. 6.11 a Programme Package for Multivariate Calibration; CAMO ASA: Trondheim, Norway, 1997.

(19) Martens, H.; Naes, T. Partial least squares regression. Multivariate Calibration; J. Wiley and Sons: Chichester, U.K., 1989; pp 116-165.

(20) Dixon, J.; Hewett, E. W. Factors affecting apple aroma/flavour volatile concentration: a review. N. Z. J. Crop Hortic. Sci. 2000, $28,155-173$

(21) Brackmann, A.; Streif, J.; Bangerth, F. Relationship between a reduced aroma production and lipid metabolism of apple after long-term controlled-atmosphere storage. J. Am. Soc. Hortic. Sci. 1993, 118, 243-247.

(22) Echeverría, G.; Graell, J.; López, M. L.; Lara, I. Volatile production, quality and aroma-related enzyme activities during maturation of 'Fuji' apples. Postharvest Biol. Technol. 2004, 32 (1), 29-44.

Received for review October 31, 2003. Revised manuscript received March 22, 2004. Accepted March 23, 2004. We thank projects CICYT, ALI98-0960-C02-02 and ALI98-0960-C02-01, and project INIA (RTA 02-072) for their financial support and INIA for a FPI Grant conceded to G.E.

JF035271I 